\title{
Do local elections predict the outcome of the next general election? Forecasting British general elections from local election national vote share estimates
}

DOI:

10.1016/j.electstud.2015.11.008

\section{Document Version \\ Accepted author manuscript}

Link to publication record in Manchester Research Explorer

Citation for published version (APA):

Prosser, C. (2016). Do local elections predict the outcome of the next general election? Forecasting British general elections from local election national vote share estimates. Electoral Studies, 41, 274-278.

https://doi.org/10.1016/j.electstud.2015.11.008

\section{Published in:}

Electoral Studies

\section{Citing this paper}

Please note that where the full-text provided on Manchester Research Explorer is the Author Accepted Manuscript or Proof version this may differ from the final Published version. If citing, it is advised that you check and use the publisher's definitive version.

\section{General rights}

Copyright and moral rights for the publications made accessible in the Research Explorer are retained by the authors and/or other copyright owners and it is a condition of accessing publications that users recognise and abide by the legal requirements associated with these rights.

\section{Takedown policy}

If you believe that this document breaches copyright please refer to the University of Manchester's Takedown Procedures [http://man.ac.uk/04Y6Bo] or contact uml.scholarlycommunications@manchester.ac.uk providing relevant details, so we can investigate your claim.

\section{OPEN ACCESS}




\title{
Do local elections predict the outcome of the next general election?
}

Forecasting British general elections from local election national vote share estimates

\author{
Christopher Prosser \\ University of Manchester
}

chris.prosser@manchester.ac.uk

Electoral Studies, 41, pp. 274-278, 2016.

\begin{abstract}
This paper outlines a method for forecasting British general elections from national level vote shares at local elections. Although local elections are notionally 'local', the evidence suggests that they at least partly mirror national electoral fortunes. A simple general election vote share on local election vote share regression model that accounts for partisan differences and incumbency effects fits past data with reasonable accuracy. Based on the results of the 2013 and 2014 local elections, the model forecast a $56 \%$ probability of hung parliament, with a $78 \%$ probability of the Conservatives receiving the largest share of the vote.

, local elections,
\end{abstract}


Local elections in the United Kingdom are regularly used by politicians and political commentators as barometers of public support for governments and parties between general elections. Although they are officially concerned with local issues and determine the composition of local government, success and failure across the pooled election results are frequently taken to be a 'triumph' or a 'disaster' for the national level political parties and their leaders. Most evaluations of party performance at local elections treat the results as a 'nowcast' and offer their conclusions as to what would happen at a General Election if the local results were repeated. This paper seeks instead to assess the predictive capacity of local elections and develops a simple method for forecasting future general election outcomes by accounting for predictable variation between local and general elections.

The paper proceeds as follows: First It explores the potential benefits and pitfalls of using local election results as a source of information about future elections and introduces the two measures of national level results used in the forecast. Second it develops a method for forecasting vote shares at future general elections from national vote estimates at local elections. Third it outlines the method used here for converting vote share forecasts into seat forecasts. Finally it presents the forecast for the 2015 general election based on the results of the 2013 and 2014 local elections.

\section{National results from local elections}

In their present form, local elections have been held annually in England and Wales since 1973, following the passage of the Local Government Act 1972, with a rotating combination of different councils facing election each year. ${ }^{1}$ That this is the case presents a number of challenges for using local elections to forecast future general elections: they do not include local elections in Scotland (which are all held on a separate, five year, cycle) and the different combinations of councils in different years may yield wildly different national level aggregations of votes cast, and indeed no official national level results are reported.

Fortunately these problems are overcome thanks to two estimates of the GB national (e.g. including Scotland) vote performance of the main parties at local elections as if they were held in similar circumstances to general elections - that is, they were held nationally and the main parties fielded candidates in every ward/division. The first, the National Equivalent of the Vote (NEV) is produced by Colin Rallings and Michael Thrasher and published by the Sunday Times, and is available for every election since 1980. The second, the Projected National Share (PNS), is produced by the BBC, and is available from 1982 onwards. $^{2}$

The forecasting model developed here in essence uses NEV and PNS national vote shares as if they were large scale opinion polls. Used in this way, local elections results have two potential advantages over conventional polling: first in terms of their sheer scale, and second that the information they provide is based on actual voting behaviour rather than reported intentions.

Using local election results to forecast general elections has several obvious disadvantages, not least the limited amount of information that is available - there are only 27 local elections that have the necessary NEV results and 25 that have the PNS results, which limits the complexity and accuracy of any forecasting model.

\footnotetext{
${ }^{1}$ Councillors serve four year terms but depending on the council they are either all elected every four years, half the councillors are elected every two years, or a third of the councillors are elected every year for three years out of four, with no election held in the forth year.

${ }^{2}$ For a brief overview and comparison of NEV and PNS, see Fisher (2014).
} 
It might be argued that since local elections are about local government, their results reflect local concerns rather than national trends. However local elections might reflect national political concerns to the extent that partisanship crosses different electoral arenas and local elections are 'second order' - that is, voters use the elections in secondary electoral arenas to express their satisfaction or dissatisfaction with national level governments (Reif and Schmitt, 1980). However several authors have shown that voting in local elections is less 'second order' than voting in the classic second order case - European Parliament elections (Heath et al., 1999; Rallings and Thrasher, 2005). Despite these caveats, national politics does seem to exert at least some effect on local election behaviour (Rallings and Thrasher, 1997) suggesting that local elections are a potential source of information about future national electoral fortune. Indeed local by-election results have been used with great success to forecast general elections (Rallings et al., 2011).

Perhaps the most obvious disadvantage of using local elections to forecast general elections is the long lag between local elections and subsequent general elections - in the present election cycle the most recent local elections held before the 2010 general election were held on May 22, 2014 -almost a full year before the general election. The present election illustrates the pitfalls of such a long range forecast - the rise of the Scottish National Party during and after the Scottish independence referendum occurred after the last local elections, and so cannot be incorporated into the forecast. ${ }^{3}$

These challenges illuminate the purpose and limitations of the local elections forecasting model. It is important to make clear that it is not intended to compete on equal terms with models which can incorporate more recent information into their forecasts. Rather it is intended as an attempt to evaluate the forecasting power of a particular source of information about party support and answer the question posed in the title - do local elections predict the outcome of future general elections? The model proposed here suggests that local elections do predict future general elections, at least to some extent. This is not because the vote shares at local and subsequent national elections do not change from one election to the other, but because they do change in systematic ways. The local election model should be seen in two ways, as a (very) long range forecast of future elections, and as a way of benchmarking party performance in local elections against past electoral trends.

\section{Forecasting vote shares}

Two forecasting models are developed here - with separate models for NEV and PNS. In order to maximise the information available for each forecast from the limited data available, analysis is conducted on the pooled data of each of the three main parties (Conservative, Labour, Liberal Democrat) and the combined other vote share. The local election model can be considered a special case of a votes on polls forecast model, with polls replaced by local election vote shares. The dependent variable for each party $p$ at local election $l$, is the share of the vote they receive at the general election following the local election (general election vote $v_{p l}$ ). The main independent variable of interest is the estimate of the party's share of the national vote at the local election (local election vote $_{p l}$ ) and different specifications of the model contain dummy variables indicating the party of each case (labour , lib dem , and other ${ }_{p}$, with the Conservatives as the base outcome) and whether the party was the incumbent government party at the time of the local election (incumbent $t_{p}$ ). These dummy variables are included to control for party and government specific local election effects - on

\footnotetext{
${ }^{3}$ The additional problem of how the rise of the SNP will affect calculation of the NEV and PNS when elections are not held in Scotland remains is also a concern, and it remains to be seen how this will affect the calculation of NEV and PNS, and the applicability of the current forecasting model to future elections.
} 
average incumbent government parties tend to perform worse at local elections than they do at subsequent general elections (i.e. midterm blues), the Liberal Democrats tend to do better in local elections than they do in general elections, and the Conservatives do worse.

One piece of information is notable by its absence - how far in advance of the general election the local election is held. It seems plausible - or indeed likely - that local elections held closer to general elections will provide better a better forecast of future general elections than those held further away. However, incorporating information into the model about the time until the next election (analysis not shown here) does not improve the fit of the forecasting model and subsequent tests of the model suggest that, on average, predictions from earlier local elections are no worse than predictions from later local elections. ${ }^{4}$

Four potential forecasting models are developed with different combinations of the predictor variables: ${ }^{5}$

(1) General election vote on local election vote.

general election vote pl $=\alpha+\beta_{1}$ local vote $_{p l}+\epsilon_{p l}$

(2) General election vote on local election vote with party dummies.

general election vote $_{p l}=\alpha+\beta_{1}$ local vote $_{p l}+\beta_{2}$ labour $_{p}+\beta_{3}$ lib dem $_{p}+\beta_{4}$ other $_{p}+\epsilon_{p l}$

(3) General election vote on local election vote with the government incumbency dummy.

general election vote $_{p l}=\alpha+\beta_{1}$ local vote $_{p l}+\beta_{5}$ incumbent $_{p}+\epsilon_{p l}$

(4) General election vote on local election vote with party and government incumbency dummies.

general election vote $_{p l}=\alpha+\beta_{1}$ local vote $_{p l}+\beta_{2}$ labour $_{p}+\beta_{3}$ lib dem $_{p}+\beta_{4}$ other $_{p}+\beta_{5}$ incumbent $_{p}+\epsilon_{p l}$

The models are estimated separately for NEV and PNS using Ordinary Least Squares regression, the results of which are shown in table 1. For both NEV and PNS the analysis suggests that model 4, which incorporates local election vote shares with party and government incumbency dummies, provides the best fitting model, and so it will be used here as the forecasting model.

\footnotetext{
${ }^{4}$ It is possible (and perhaps likely) that this is due to the small amount of information available for the present method, rather than some hitherto undiscovered flatness in changes in voting behaviour over the electoral cycle. ${ }^{5}$ Other variations, including vote change models and models with interactions between local election voteand the party and incumbency dummies (i.e. to create party and government specific slopes) were also tested - the results (not shown) do not suggest any predictive gains from any of these additions.
} 
Table 1. Results from general election vote on local election vote regression models using Rallings and Thrasher's National Equivalent of the Vote (NEV) and the BBC's Projected National Share (PNS) estimates of national level support at local elections.

\begin{tabular}{|c|c|c|c|c|c|c|c|c|}
\hline & \multicolumn{4}{|c|}{ NEV } & \multicolumn{4}{|c|}{ PNS } \\
\hline & Model 1 & Model 2 & Model 3 & Model 4 & Model 1 & Model 2 & Model 3 & Model 4 \\
\hline \multirow[t]{2}{*}{ localvote } & $0.964 * * *$ & $0.301 * * *$ & $0.865^{* * *}$ & $0.446 * * *$ & $0.986^{* * *}$ & $0.411 * * *$ & $0.892 * * *$ & $0.536 * * *$ \\
\hline & $(0.041)$ & $(0.086)$ & $(0.035)$ & $(0.087)$ & $(0.043)$ & $(0.077)$ & $(0.034)$ & $(0.076)$ \\
\hline \multirow[t]{2}{*}{ labour } & & $-2.129 *$ & & -0.659 & & -0.812 & & 0.332 \\
\hline & & $(1.162)$ & & (1.135) & & (1.096) & & $(1.04)$ \\
\hline \multirow[t]{2}{*}{ libdem } & & $-12.689 * * *$ & & $-7.623 * * *$ & & $-11.989 * * *$ & & $-7.755^{* * *}$ \\
\hline & & (1.595) & & $(1.913)$ & & $(1.373)$ & & $(1.592)$ \\
\hline \multirow[t]{2}{*}{ other } & & $-23.275^{* * *}$ & & $-15.734 * * *$ & & $-19.584 * * *$ & & $-13.087^{* * *}$ \\
\hline & & $(2.802)$ & & $(3.165)$ & & $(2.477)$ & & $(2.72)$ \\
\hline \multirow[t]{2}{*}{ incumbent } & & & $8.363^{* * *}$ & $5.086 * * *$ & & & $8.441^{* * *}$ & $4.794 * * *$ \\
\hline & & & (1.04) & $(1.216)$ & & & (1) & (1.103) \\
\hline \multirow[t]{2}{*}{ constant } & 0.897 & $27.009 * * *$ & 1.283 & $18.571^{* * *}$ & 0.34 & $22.818^{* * *}$ & 0.598 & $15.525^{* * *}$ \\
\hline & $(1.162)$ & $(3.186)$ & $(0.92)$ & (3.58) & (1.193) & $(2.821)$ & $(0.911)$ & (3.084) \\
\hline $\mathrm{n}$ & 108 & 108 & 108 & 108 & 100 & 100 & 100 & 100 \\
\hline R squared & 0.837 & 0.907 & 0.899 & 0.92 & 0.845 & 0.923 & 0.911 & 0.935 \\
\hline RMSE & 5.54 & 4.257 & 4.379 & 3.952 & 5.364 & 3.856 & 4.093 & 3.537 \\
\hline
\end{tabular}

\section{From votes to seats}

In order to translate the forecast vote shares into seat share this paper adopts the method used by previous votes on polls forecasting models (e.g. Fisher, 2015; Fisher et al., 2011). This method first applies the uniform change in the share of vote in each constituency implied by the forecast national share of the vote and then uses the Curtice and Firth (2008) method of estimating the probability each party will win each.

In Curtice and Firth (2008) the probability of party $j$ winning constituency $i$ from the predicted share of the vote $s_{i j}$ is $\frac{r_{i j}}{\sum_{j} r_{i j}}$ where

$$
r_{i j}=\operatorname{excp}\left[-\left(\frac{\max _{j}\left\{s_{i j}\right\}-s_{i j}}{\sigma}\right)^{\lambda}\right]
$$

and $\lambda$ and $\sigma$ are tuning constants that have been empirically determined $(\lambda=1.5$ and $\sigma=4)$. The predicted seat total for each party is the sum of the predicted probabilities for each party across constituencies.

\section{Forecasting the $\mathbf{2 0 1 5}$ general election}

Forecasting the 2015 general election from local election results offers three challenges - one general to forecasting from local elections and two specific to the current election cycle. A general problem for forecasting from local election results is the question of which results to use. Although the results in table 1 suggest that PNS offers a slightly better fitting model the difference is small and not decisive. 
Rather than choosing between them, separate forecasts will be produced for the NEV and PNS models and the forecasts averaged to produce a final forecast. Similarly, older local election results are equally good at forecasting as more recent results, again raising the question of which set of results to use. Once more the solution that suggests itself is to produce separate forecasts for each set of local elections and average across them.

Two problems specific to forecasting the 2015 are the presence of the Liberal Democrats in government and the rise of the United Kingdom Independence Party (UKIP). As the Liberal Democrats have not previously been in government there is indication as to whether they will experience a recovery as election day gets closer, and indeed the polls suggest they will not. This forecast follows the lead of Fisher (2015) and codes the Liberal Democrats as if they were not an incumbent party.

An ad hoc solution to the problem of UKIP is simply to treat the UKIP share of the vote as if it behaves as the combined 'other' share. Additionally the forecast will only use the two most recent local elections (2013 and 2014), which took place during the period following the increased popularity of UKIP, which are also the only years for which NEV and PNS estimates of the UKIP share of the vote are available.

Table 2 shows the input vote estimates and point estimate forecasts for each party for each national vote estimate for the 2013 and 2014 local elections. The forecast are remarkably similar and consistently forecast that the Conservatives will have a higher share of the votes at the 2015 general election.

Table 2. Input local election vote share and forecast general election vote share.

\begin{tabular}{|c|c|c|c|c|c|c|c|c|}
\hline & \multicolumn{4}{|c|}{ NEV } & \multicolumn{4}{|c|}{ PNS } \\
\hline & \multicolumn{2}{|c|}{2013} & \multicolumn{2}{|c|}{2014} & \multicolumn{2}{|c|}{2013} & \multicolumn{2}{|c|}{2014} \\
\hline & Input & Forecast & Input & Forecast & Input & Forecast & Input & Forecast \\
\hline Conservatives & 26 & 35.3 & 30 & 36.1 & 25 & 33.7 & 29 & 35.9 \\
\hline Labour & 29 & 30.9 & 31 & 31.8 & 31.4 & 29 & 31 & 32.5 \\
\hline $\begin{array}{c}\text { Liberal } \\
\text { Democrat }\end{array}$ & 13 & 16.8 & 11 & 15.9 & 14 & 15.3 & 13 & 14.7 \\
\hline UKIP & 22 & 12.7 & 18 & 10.9 & 23 & 14.8 & 17 & 11.6 \\
\hline
\end{tabular}

Combined, these forecasts yield an average vote share forecast of:

Conservatives: $35.25 \%$

Labour: 31.05\%

Liberal Democrat: $15.675 \%$

UKIP: $12.5 \%$

Which gives a forecast seat share for the three major parties of:

Conservatives: 296

Labour: 287

Liberal Democrat: 38

Unsurprisingly given the small amount of information used to make the forecast and the long lag between predictor local vote shares and forecast general election vote shares there is a high degree of uncertainty in the forecast. Figure 1 illustrates this uncertainty and shows the distribution of error 
implied by the standard error of the forecast for each prediction. From these distributions probabilities of key events can be calculated. Averaging across forecasts, this gives the Conservatives a $78 \%$ chance of winning the most votes. Calculating the forecast seat shares by using the vote forecast altered by the standard error of the forecast gives an approximate distribution of the probability of different seat shares. Using this distribution the probability of there being a hung parliament is $56 \%$ and the probability of the Conservatives being the largest party is $55 \%$.

Figure 1. Uncertainty of forecast vote shares.
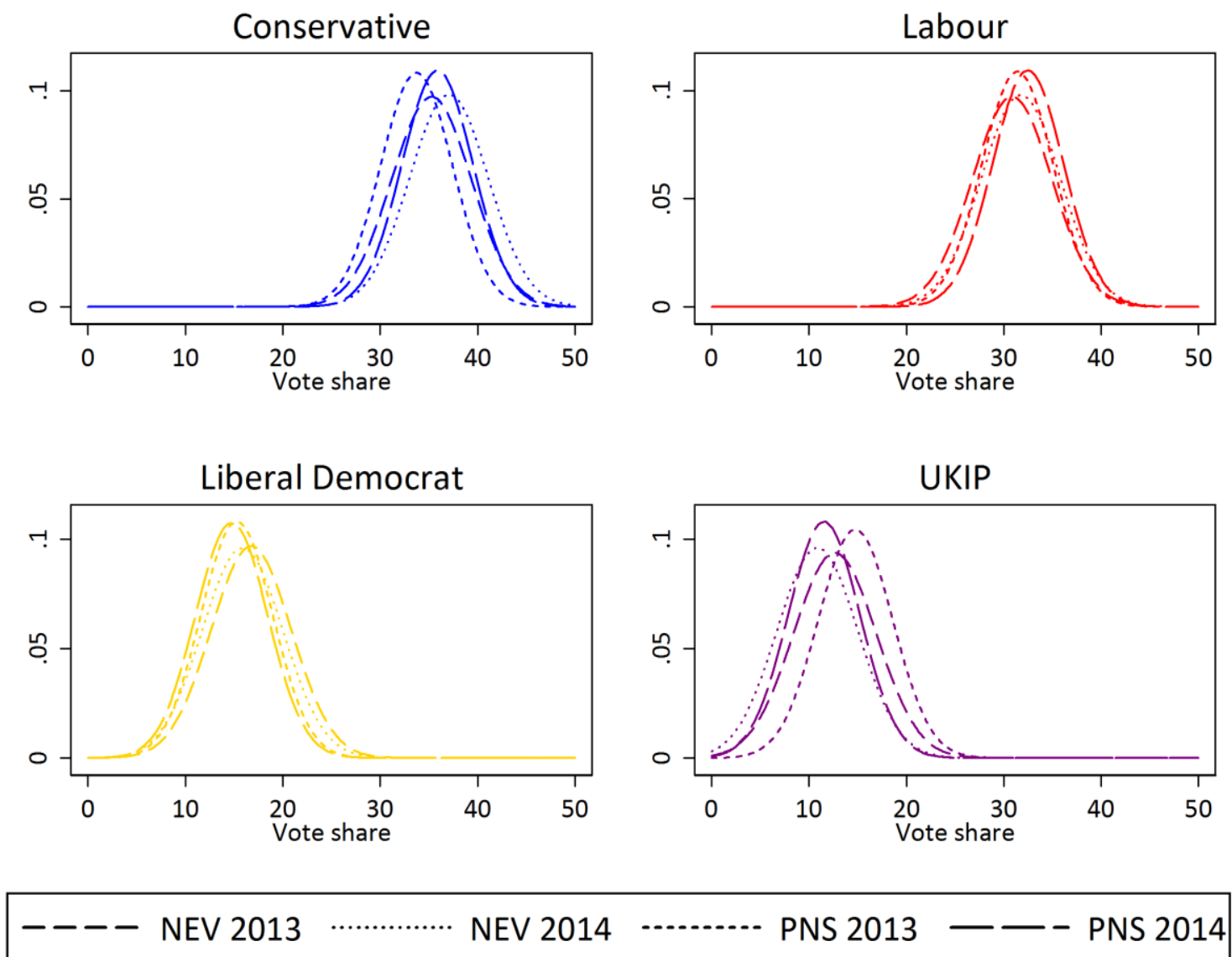

How will this forecast fare? From the vantage point of the eve of the 2015 general election, two estimates seem particularly over optimistic: the Labour share of seats and the Liberal Democrat share of the vote and seats. That the Labour share of seats seems optimistic is entirely due to the rise of the SNP and the inability of the local election forecast model to take this information into account. That the Liberal Democrat forecasts are optimistic reflects two things: one, regression to the mean - the current Liberal Democrat performance in the polls is much poorer than their average performance at local elections, and two, although the Liberal Democrat have performed poorly in local elections during the 2010-2015 electoral cycle, they have still outperformed their polling position.

On two key questions - whether there will be a hung parliament, and which party will have the largest number of seats - the forecast is remarkably similar to other forecasts which can incorporate a much larger amount of - and more recent - information. Given that the forecast here is based on a combination of information that is either one or two years old, this is no mean feat. This suggests that 
when used in a very simple forecasting model, local elections can provide a valuable source of information about future electoral performance.

\section{Post-election postscript}

Given the modest expectations of a simple model and the lag between local election results and the general election, the local election forecast model performed fairly well in its forecast of the 2015 election. The forecast vote shares (table 3 ) for Labour and UKIP were both within half a point of the result. The forecast Conservative vote share was less accurate, underestimating the Conservative vote by 2.45 points, though the model still predicted a clear Conservative lead over Labour and indeed was closer to the actual result than the eve of election opinion polls. It is worth noting that the different forecasts consistently predicted the Conservatives would be ahead despite the fact that Labour was ahead in all of the input local vote shares (table 2). As predicted in the pre-election commentary, the forecast Liberal Democrat share of the vote was a drastic overestimate - the actual result was almost half that of the forecast.

Table 3. Forecast and actual vote shares.

\begin{tabular}{|c|c|c|c|}
\hline Party & Forecast vote \% & Actual Vote \% & Error \\
\hline Conservative & 35.25 & 37.7 & -2.45 \\
\hline Labour & 31.05 & 31.2 & -0.15 \\
\hline Liberal Democrat & 15.675 & 8.1 & 7.575 \\
\hline UKIP & 12.5 & 12.9 & -0.4 \\
\hline
\end{tabular}

The seat forecast fared less well, as shown in table 4 (which also includes the UKIP forecast of zero seats, unintentionally omitted in the pre-election write up). Like most other forecasts, the local election model incorrectly predicted a hung parliament, though it was less bullish than some forecasts, with a $44 \%$ chance of a majority. This can largely be accounted for by three factors: First, under predicting the Conservative lead in vote share. Second, the rise of the SNP in Scotland accounts for many of the over forecast Labour seats (as predicted in the pre-election write up). Excluding the Scottish seats from the calculation, the forecast vote shares translate into 244 Labour seats, considerably closer to the mark than the forecast including Scotland of 287. And third, even with the correct vote shares input, the Curtice and Firth (2008) votes to seats method over predicts Labour and Liberal Democrat seats and under predicts Conservative seats outside of Scotland, suggesting a shift in the pattern of vote to seat translation in British elections. The only way the seat forecast would have been accurate would have been if the vote forecast had drastically overestimated the Conservative vote share, and underestimated the Labour and Liberal Democrat vote shares.

Table 4. Forecast and actual seat shares.

\begin{tabular}{|l|l|l|l|}
\hline Party & Forecast Seats & Actual Seats & Error \\
\hline Conservative & 296 & 330 & -34 \\
\hline Labour & 287 & 232 & 55 \\
\hline Liberal Democrat & 38 & 8 & 30 \\
\hline UKIP & 0 & 1 & 1 \\
\hline
\end{tabular}

The model performed very well on Labour and UKIP vote shares, modestly well on Conservative vote share and Conservative-Labour lead, less well on seat allocation and fared worst where it was 
expected to - in its forecast of the number of Labour seats, and Liberal Democrat vote share and number of seats. Overall this suggests that, with some adjustments (particularly the question of how to incorporate information about Scotland into the model), local elections might offer a promising source of data for future long range election forecasting. 


\section{References}

Curtice, J., Firth, D., 2008. Exit polling in a cold climate: the BBC-ITV experience in Britain in 2005. Journal of the Royal Statistical Society: Series A (Statistics in Society) 171, 509-539. doi:10.1111/j.1467-985X.2007.00536.x

Fisher, S.D., 2014. Elections etc: Local Elections Vote Shares: the BBC PNS and Rallings \& Thrasher NEV compared. http://electionsetc.blogspot.co.uk/2013/05/local-elections-vote-shares-bbc-pnsand.html

Fisher, S.D., 2015. Predictable and Unpredictable Changes in Party Support: A Method for Long-Range Daily Election Forecasting from Opinion Polls. Journal of Elections, Public Opinion and Parties 25, 137-158. doi:10.1080/17457289.2014.952732

Fisher, S.D., Ford, R., Jennings, W., Pickup, M., Wlezien, C., 2011. From polls to votes to seats: Forecasting the 2010 British general election. Electoral Studies, Special Symposium: Electoral Forecasting Symposium 30, 250-257. doi:10.1016/j.electstud.2010.09.005

Heath, A., McLean, I., Taylor, B., Curtice, J., 1999. Between first and second order: a comparison of voting behaviour in european and local elections in britain. European Journal of Political Research 35, 389-414. doi:10.1111/1475-6765.00454

Rallings, C., Thrasher, M., 2005. Not All "Second-Order" Contests are the Same: Turnout and Party Choice at the Concurrent 2004 Local and European Parliament Elections in England*. The British Journal of Politics \& International Relations 7, 584-597. doi:10.1111/j.1467856X.2005.00207.x

Rallings, C., Thrasher, M., 1997. Local Elections in Britain. Routledge.

Rallings, C., Thrasher, M., Borisyuk, G., Long, E., 2011. Forecasting the 2010 general election using aggregate local election data. Electoral Studies, Special Symposium: Electoral Forecasting Symposium 30, 269-277. doi:10.1016/j.electstud.2010.09.011

Reif, K., Schmitt, H., 1980. Nine Second-Order National Elections - A Conceptual Framework for the Analysis of European Election Results. European Journal of Political Research 8, 3-44. 